\begin{tabular}{|c|c|c|}
\hline 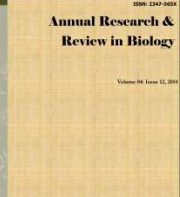 & $\begin{array}{c}\text { Annual Research \& Review in Biology } \\
\text { 9(1): 1-8, 2016, Article no.ARRB.22707 } \\
\text { ISSN: 2347-565X, NLM ID: } 101632869\end{array}$ & $\underbrace{}_{\text {SCIENCEDOMAIN }}$ \\
\hline | & $\begin{array}{c}\text { SCIENCEDOMAIN international } \\
\text { www.sciencedomain.org }\end{array}$ & \\
\hline
\end{tabular}

\title{
Retrospective Study of 33 Dogs Diagnosed with Osteosarcoma (OSA) by Fine Needle Aspiration Cytology (FNAC) at FMVZ Vet Hospital, UNESP- Botucatu, SP
}

\author{
Maurício Orlando Wilmsen ${ }^{1}$, Tália Missen Tremori ${ }^{{ }^{*}}$ and Noeme Sousa Rocha ${ }^{1}$ \\ ${ }^{1}$ Department of Veterinary Clinic, State University of Sao Paulo, UNESP, Botucatu, Brazil.
}

Authors' contributions

This work was carried out in collaboration between all authors. Author NSR designed the study and wrote the protocol. Author MOW anchored the field study, gathered the initial data and performed preliminary data analysis. While author TMT managed the literature searches and produced the initial draft. All authors read and approved the final manuscript.

Article Information

DOI: $10.9734 / A R R B / 2016 / 22707$ Editor(s):

(1) Severino Rey Nodar, Department of Pathology, Hospital Enrique Garcés, International University of Ecuador,

(2) George Perry, Dean and Professor of Biology, University of Texas at San Antonio, USA. Reviewers:

(1) Jorge Paredes Vieyra, Universidad Autónoma de Baja California-Campus Tijuana, Mexico. (2) Maen Mahfouz, Al Zafer Hospital, Saudi Arabia. Complete Peer review History: http://sciencedomain.org/review-history/12591

Original Research Article

Received $21^{\text {st }}$ October 2015 Accepted $26^{\text {th }}$ November 2015 Published ${ }^{\text {th }}$ December 2015

\section{ABSTRACT}

Aim of Study: Evaluate cases of dogs with osteosarcoma, when diagnoses using FNAC.

Study Design: A retrospective study, from archive at Veterinary Hospital, selected 33 dogs of different races, 23 females $(69.6 \%)$ and 10 males (30.3\%) were addressed, the age of tested dogs ranged from 1 to 15 years, with diagnoses of osteosarcoma using FNAC. These animals are classified according to localization of tumor, cytopathology evaluation and radiography exam.

Results: In this study, a general OSA prevalence on appendicular skeleton of $90.9 \%$ (30), being humerus and axial skeleton 9.1\% (3). Likewise, the highest age incidence ranged from 6 to 15 years $(78.7 \%) .33$ of 24 animals $(72.7 \%)$ had tumor complications in forelimbs discriminated from high to low incidence: $17(51.5 \%)$ left forelimbs (LFL,) and 7 (27.3\%) right forelimbs (RFL). Cancer signs also appeared in axial skeleton of 2 individuals (6.5\%), and paranasal sinus of another 
(3.2\%). Cytoplasmic and nuclear characteristics showed atypical mitosis in 31 (93.9\%), and multinucleated cells in $33(100 \%)$ on evaluated specimens.

Conclusion: The use of FNAC demonstrated to be a simple, quick, efficient, minimally invasive, and inexpensive diagnostic tool.

Keywords: Fine-Needle Aspiration Cytology (FNAC); bone neoplasm; canine.

\section{INTRODUCTION}

Osteosarcoma (OSA) is the most common primary bone tumor in dogs, having a malignant mesenchymal origin. Highly aggressive and invasive, OSA is initially confined to local bone microenvironment, but also involves distant organs according to tumor progression $[1,2]$.

This cancer usually affects long bones with rapid growth, which eventually causes early death due to metastatic potential mainly on lungs [3]. Compromised bone site undergoes rapid resorption, resulting in the release of growth factors and cytokines. Such condition accelerates vascularization and favors metastasis [4].

Thus, cortical lysis and periosteal damage appear due an exacerbated activity and proliferation of osteoblast cells. Consequently, bone pain comes after being compromised its structural integrity [5]. Because similarities in biology and tumor treatment, major differences between dogs and humans are based on the age of occurrence, location, and use of chemoprophylaxis [6].

Three osteosarcoma locations are commonly found in the canine skeletal system: long bones, axial skeleton, and extraskeletal manifestation. In long bones (appendage), 75\% of neoplasia cases involve humerus, femur, radius, ulna and tibia [7]. Axial osteosarcoma has $24 \%$ of incidence, mainly in the skull bones, spine, and pelvis [8]. Extraskeletal cases represent only 1\% of this cancer in dogs [9]. Some breeds (medium, large, and giant) have higher diagnostic rates (Rottweiler, Saint Bernard, Great Dane, Irish Setter, Doberman, German Shepherd, Golden Retriever, and Greyhounds). However, predisposition is related to size, not to race $[10,11]$.

Oncological diagnosis in veterinary medicine still lack effectiveness, which directly jeopardizes survival of cancer patients. Therefore, this review emphasizes the use of Fine Needle Aspiration Cytology (FNAC) as a precise and rapid diagnostic method for osteosarcoma lesions.
This medical tool has become more prevalent in recent years as a less invasive, simple, accurate, and low-cost medical procedure, with high ambulatory applicability and a rapid diagnostic response. In addition, the implied absence of anesthetic procedures benefits critically ill patients. Quality and quickness of examination results increase treatment success by enabling medical staff to adopt suitable and opportune therapeutic measures [12].

FNAC is already widely used for diagnosis of hyperplasia, inflammation, cancer and degenerative diseases. In veterinary medicine, it has been a helpful technique for oncological diagnosis since the 1980s [13].

Nowadays, FNAC is considered as a technological breakthrough to scrutinize bone neoplasm in animals [13,14]. In conjunction with traditional diagnostic methods, it may favor tumor staging when aggregated to the clinical treatment protocol [15]. Other advanced imaging technologies such as scintigraphy, computed tomography and magnetic resonance allow a more detailed assessment of features and extent of the malignancy. Nevertheless, these tests are not always available [16].

According to WYPJI, 2011, FNAC sensitivity ranges from 92 to $97 \%$ when applied in bone tumors. In this way, this study aimed to evaluate the use of fine needle aspiration cytology as a primary diagnosis tool to assess osteosarcoma cases attended by the Veterinary Hospital of the Faculty of Veterinary Medicine and Zootechny, FMVZ-UNESP, Botucatu.

\section{MATERIALS AND METHODS}

From January 2010 to June 2015, a retrospective study of osteosarcomas cases was carried out in dogs treated at the Veterinary Hospital of the Faculty of Veterinary Medicine and Zootechny, FMVZ-UNESP, Botucatu. 33 dogs selected of different breeds, 23 females and 10 males were addressed, the age of tested dogs ranged from 1 to 15 years. Information was obtained on clinical 
and radiological examination (Figs. 1, 2), and then sent to the pathology service to collect samples for cytological examination and diagnosis of osteosarcoma (Table 1).

FNAC technique was performed through $10-\mathrm{ml}$ syringes with $25 \times 7 \mathrm{~mm}$ disposable needles coupled to a Valery cytoaspirator. Sampling place was submitted to antisepsis, according to hygienic and sterilization protocols. Then, localized punctures were executed by needle insertion, followed by continuous aspirations and a quick "fan" positioning to obtain specimens by capillary action. Once finished collecting, needle contents were placed on microscope slides for smear. Samples were immediately fixed in 95\% ethanol for later Papanicolau staining. For Romanowsky method (Diff-Quick and Giemsa staining), all biological material was air dried and fixed in methanol. Cytomorphological diagnosis was made by optical microscopy with $400 x$ power (Figs. 3, 4) [17,18].

\subsection{Steps of this Study}

1. Selected dogs with diagnosis of osteosarcoma from the archive and obtained data

2. Interpretation of clinical exam

3. X-ray exam

4. Cytopathology

5. Evaluation of cases

\section{RESULTS AND DISCUSSION}

OSA diagnostic prevalence of appendicular skeleton in the specimens was $90.9 \%$ (30), and axial skeleton $9.1 \%$ (3). No case of extraskeletal manifestation was recorded.

The main symptoms reported by animal owners at consultation time were claudication (21), swelling in compromised regions (12) and hyporexia (4). These results corroborate those acute or chronic claudication, and localized edema in the affected limb [19].

Pain was present in all animals during physical examination. However, owners did not frequently identify such a condition. Sometimes animal avoids supporting affected limb due to pain caused by affected area augmentation. Pain and lameness may be related to microfractures, periosteum rupture, and major bone fracture, according tumor evolution [20-23].

Studied dogs belonged to largest type, OSA frequency in large and giant breed dogs is on average 125 times greater in dogs weighing more than 36 kilograms than those with 9 kilos and less [24-26].

Of the 33 animals diagnosed with OSA, 20 belonged to the Rottweiller breed $(60.6 \%), 6$ mongrels (18.18\%), 5 Pitbulls (15.15\%), and 2 Bloodhounds (6.06 \%) (Table 1) $[11,24,27,28]$.

Table 1. Frequency and percentage distribution of specimens by breed, gender, age and affected limb

\begin{tabular}{llll}
\hline Variable & Category & Frequency & Percentage (\%) \\
\hline Breed & Rottweiler & 20 & $60,6 \%$ \\
& SRD & 6 & $18,1 \%$ \\
& Pitbull & 5 & $15,1 \%$ \\
Gender & Blood Hound & 2 & $6,06 \%$ \\
& Total & $\mathbf{3 1}$ & $\mathbf{1 0 0}$ \\
Age & Female & 23 & $69,9 \%$ \\
& Male & 10 & $30,3 \%$ \\
Affected limb & Total & $\mathbf{3 1}$ & $\mathbf{1 0 0}$ \\
& 1 a 5 & 7 & $21,3 \%$ \\
& 6 a 15 & 26 & $78,7 \%$ \\
& Total & $\mathbf{3 1}$ & $\mathbf{1 0 0}$ \\
& Left forelimb & 17 & $51,5 \%$ \\
& Right forelimb & 7 & $21,2 \%$ \\
& Left hindlimb & 6 & 19,3 \\
& Right hindlimb & 5 & 16,2 \\
& Thoracic region & 2 & 6,5 \\
& Paranasal sinuses & 1 & 3,2 \\
\hline
\end{tabular}


Sick females prevailed $69.6 \%$ (23) over $30.3 \%$ of males (10), especially among animals with a definitive diagnose of appendicular osteosarcoma (Table 1). OSA cases in bitches tend to be higher when compared to male dogs. However, some authors establish some differences related to neoplasia kind and gender: males suffer more from appendiceal manifestation, and females from axial type $[7,22,29-31]$.

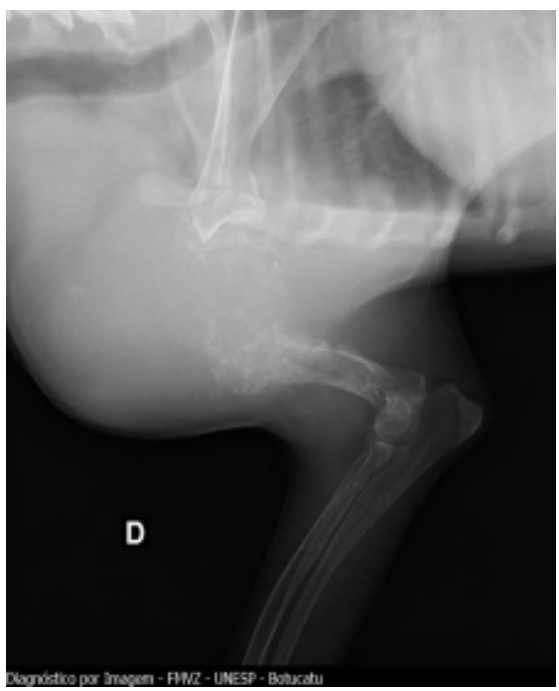

Fig. 1. Conventional radiography of right forelimb showing increased volume in humerus

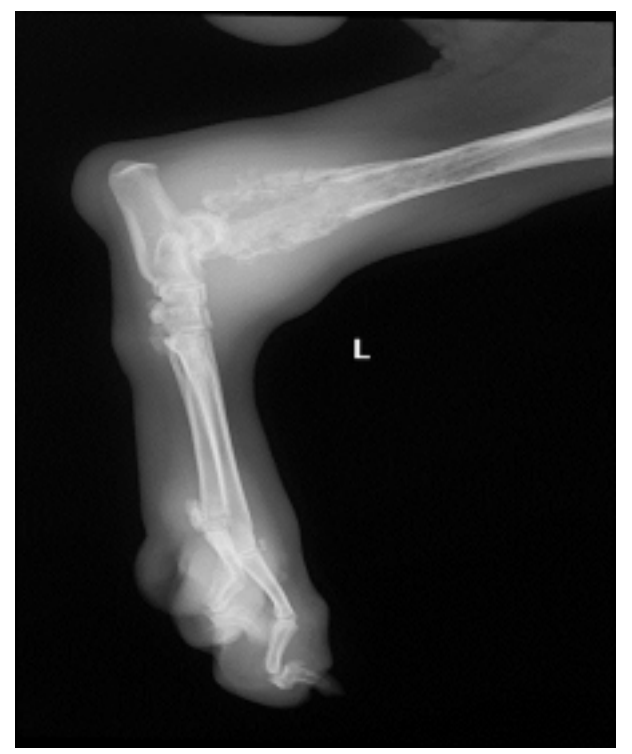

Fig. 2. Conventional radiography of pelvic limb with swelling in the distal tibia region
The age of tested dogs ranged from 1 to 15 years with an average of $7.25 \pm 3.1$. Specifically, of 33 animals, $26(78.7 \%)$ had between 6 and 15 years, and $7(21.2 \%)$ between 1 and 5 years, and its increased age is important risk factor for the development of canine osteosarcoma (Table 1) [27,32].

The highest frequency of OSA in dogs occurs at forelimbs, which bear $60 \%$ of body weight, followed by hindlimbs. In this research, 33 of 24 assessed specimens $(72.7 \%)$ had tumor at forelimb. Results clearly showed a major incidence $(51.5 \%)$ on left forelimb (LFL), with 17 cases, than those on right forelimb (RFL), with 7 $(27.3 \%)$. These results match those found by Silveira et al. [30]: $40 \%$ of positive outcomes in LFL, and $34 \%$ in RFL $[33,34]$.

Concerning compromised bones, the humerus had the major rate with 15 cases $(45.4 \%)$, followed by the tibia region with 9 (27.2\%). Humerus, tibia, radius, ulna, and femur, as the more affected (Figs. 1, 2). 15 of 33 animals with OSA in humerus, 11 (33.3\%) belonged to Rottweiller breed. Some races are more susceptible than others to suffer from humeral neoplasia, as Rottweiller already is [22,29].

Proximal humeral region had the higher proportion of lesions. 16 of the 24 animals showed tumors in this area $(66.6 \%)$, and 8 $(33.3 \%)$ at the distal portions of radius/ulna, with joint affection. These findings are consistent with those pointed out in previous investigations, $60 \%$ of osteosarcoma cases are located in such bone area, followed by the distal region of femur. In the present study, the latter only occurred in 3 cases $(9,07 \%)[21,25,30,34]$.

In the case of OSA at axial skeleton, outcomes showed low prevalence: 2 animals $(6.5 \%)$ in ribs, and $1(3.2 \%)$ in paranasal sinus. These results concur with those found for others authors when referred to axial OSA incidence from $2 \%$ to $5 \%$ among ill dogs. In all, locations commonly affected are jaw (27\%), jaw (22\%), spine (15\%), skull $(14 \%)$, ribs $(10 \%)$, nasal cavity and paranasal sinuses $(9 \%)$, and pelvis $(6 \%)$, respectively $[8,31,35,36]$.

When seeking possible metastatic foci by radiological evaluation, $25(86.2 \%)$ of 29 dogs showed no change, and $8(27.5 \%)$ had nodules highly suggestive of pulmonary metastasis. Identifying lung metastases is possible in less than $10 \%$ cases at the consultation time [37]. 


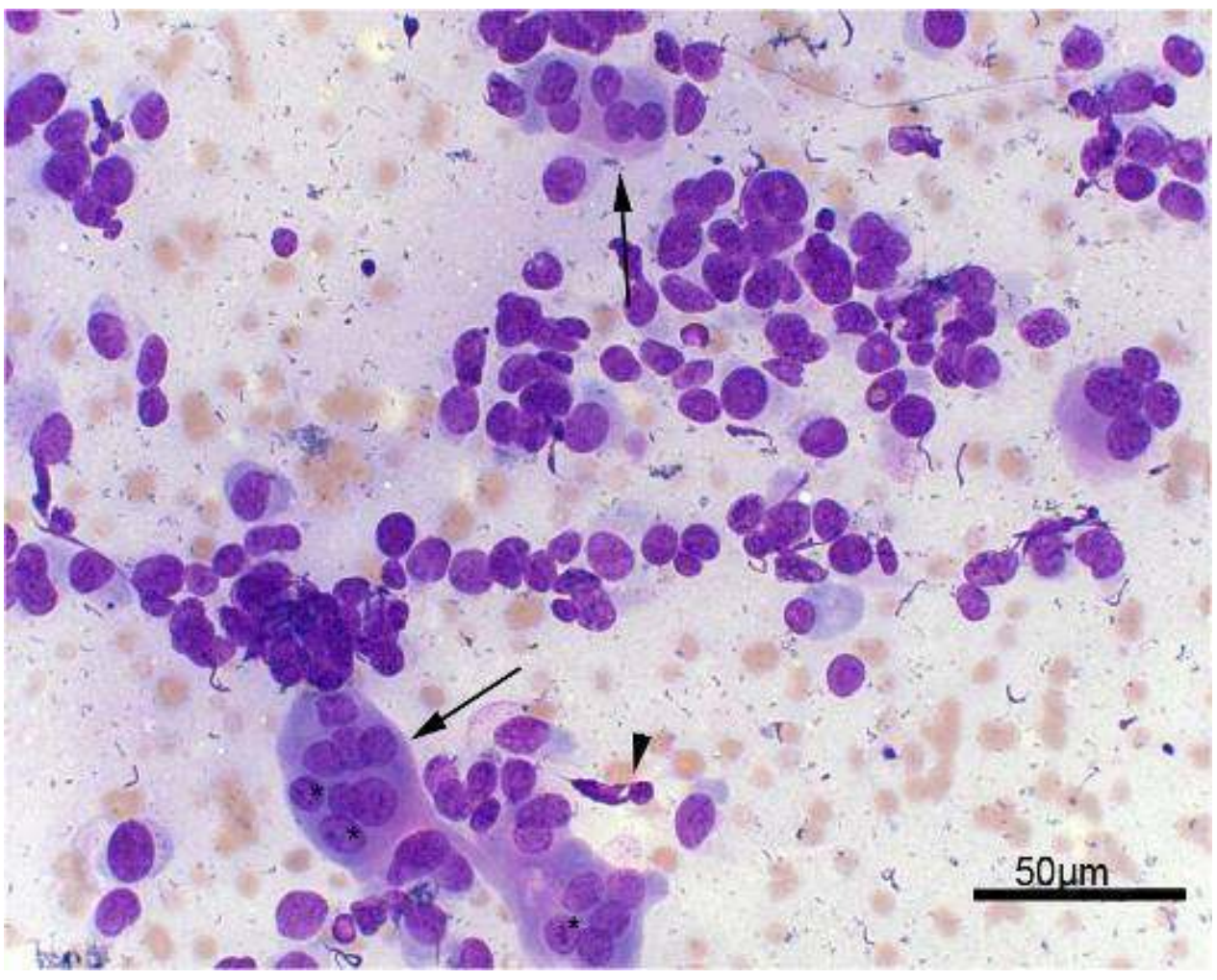

Fig. 3. Arrowhead: Bare cells. Arrows: Bone matrix. Giemsa, 40x

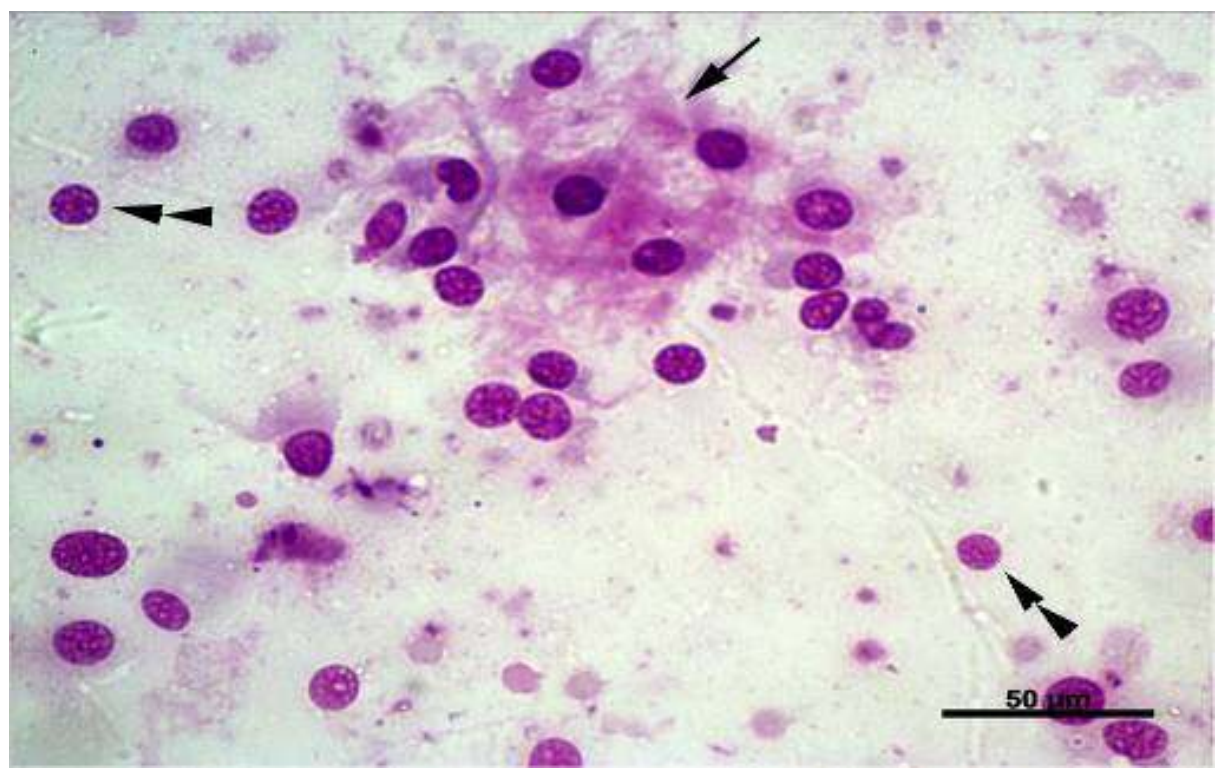

Fig. 4. Arrows: Osteoclasts. Arrowhead: Fusiform cell. Asterisks: Evident nucleolus. Giemsa, 40x

In summary, FNAC was performed in the attended animals (33) to evaluate cytoplasmic characteristics, nuclear, chromatin condensation, giant cells and atypical mitosis, beyond malignancy criteria (Fig. 3). Atypical mitosis cells were found in 31 specimens $(93.9 \%)$, and 
multinucleated cells in all of $33(100 \%)$. Cytology enables to demonstrate neoplastic processes by means of microscopic cell evaluation [33,38].

Regarding nuclear features, clear nucleoli were observed in 29 cases (87.8\%) and anisocariose in $30(90.9 \%)$ (Fig. 4). About cell cytoplasmic changes, little vacuolated had 17 incidences (51.5\%), basophilic core 27 (81.8\%), and conspicuous cytoplasm only $2(2.06 \%)$. In the case of chromatin condensation, coarse chromatin was present in 25 samples (75.7\%), and the firm type in $32(96.9 \%)$ of the evaluated animals. In literature, anisocariose, littlevacuolated basophilic cytoplasm, and coarse nuclear chromatin, may indicate a significant aggressive potential of this cancer [38].

Some treatment options considered clinical conditions of patient, options for life quality improvement, and owner decisions after facing examination results.

14 animals (42.4\%) underwent surgery (affected limb amputation). The amputation is the main treatment choice to remove the major focus of pain. Due to the advanced stage of cancer, 17 $(51.5 \%)$ animals were euthanized because poor prognosis. Only one animal required limb amputation surgery and chemotherapy. Limb amputation, combined with an appropriate chemotherapy, as the best therapy to increase animal survival. Likewise, one animal did not return to the clinic for service sequence after primary consultation and diagnosis [33,39].

\section{CONCLUSION}

Facing poor survival of OSA patient and limited therapeutic options, the use of FNAC demonstrated to be a simple, quick, efficient, minimally invasive, and inexpensive diagnostic tool. Given its importance for veterinary medicine, the findings suggest that further studies should be done in order to standardize and improve FNAC method.

\section{CONSENT}

It is not applicable.

\section{ETHICAL APPROVAL}

It is not applicable.

\section{COMPETING INTERESTS}

Authors have declared that no competing interests exist.

\section{REFERENCES}

1. Marley K, Shay B, Bernard S. Osteoprotegerin, activates cells that coexpress RANK and RANKL. Experimental Cell Research. 2015;338(1):32-38.

2. Wycislo KL, Fan TM. The immunotherapy of canine osteosarcoma: A historical and systematic review. Journal Veterinary Internal Medicine. 2015;29:759-769.

3. Lamourex $F$, Richard $P$, Wittrant $Y$, Battaglia S, Pilet P, Trichet V, Blanchard F, Gouin F, Pitard B, Heymann D, Redini F. Therapeutic relevance of osteprotegerin Gene therapy in osteosarcoma: blockade of the vicious cycle between tumor cell proliferation and bone reabsorption. Cancer Research. 2007;67:7308-7318.

4. Guise TA, Mohammad KS, Clines G, Stebbins EG, Higgins LS, Vessella $R$, Corey E, Padalecki S, Suva L, Chirgwin JM. Basic mechanisms responsible for osteolytic and osteoblastic bone metastases. Clinical Cancer Research. 2006;15:6213-6216.

5. Luetke A, Meyers PA, Lewis I, Juergens $H$. Osteosarcoma treatment - Where do we stand? A state of the art review. Cancer Treatment Reviews. 2014;40:523-532.

6. Morello E, Martano M, Buracco P. Biology, diagnosis and treatment of canine appendicular osteosarcoma: Similarities and differences with human osteosarcoma. The Veterinary Journal. 2011;189:268277,.

7. Dickerson ME, Page RL, Ladue TA, Hauck ML, Thrall DE, Stebbins ME, Price GS. Retrospective analysis of axial skeleton osteosarcoma in 22 large breed dogs. Journal Veterinary Internal Medicine 2001;15:120-124.

8. Hammer AS. Prognostic factors in dogs with osteosarcoma of the flat or irregular bones. Journals the American Animal Hospital Association. 1995;31:321-326.

9. Stimson EL, Cook WT, Smith MM, Forrester SD, Moon ML, Saunders GK. Extraskeletal osteosarcoma in the duodenum of cat. Journal of the American Animal Hospital Association. 2000;36:332336.

10. Rosenberger JA, Pablo NV, Crawford PC. Prevalence of intrinsic risk factors for appendicular osteosarcoma in dogs: 179 cases (1996-2005). Journal of the 
American Veterinary Medical Association. 2007;23:1076-1080.

11. Ru G, Terracini B, Glickman LT. Host related risk factors for canine osteosarcoma. Veterinary Journal. 1998; 156:31-39.

12. Wypji JM. Getting to the point: Indications for fine-needle aspiration of internal organs and bone. Topics in Companion Animal Medicine. 2011;26:77-85.

13. Magalhães $A M$, Ramadinha RR, Barros CSL, Peixoto PV. Comparative study between citopathology and histopathology in diagnostico of canine tumors. Pesquisa Veterinária Brasileira. 2001;21:23-32.

14. Cassone AE, Barbi- Gonçalves JC, Aguiar S. Eficácia da biópsia com agulha nos tumores ósseos. Revista Brasileira de Ortopedia. 1996;31:891-894.

15. Lamb CR, Berg J, O'callaghan MW. Bone scintigraphy in the initial evaluation of dogs with primary bone tumors. Journal of the American Animal Hospital Association. 1990;196(6).

16. Davis GJ, et al. Comparison of radiography, computed tomography, and magnetic resonance imaging for evaluation of appendicular osteosarcoma in dogs. Journal of the American Animal Hospital Association. 2002;220:1171-1176.

17. Raskin RE, Meyer DJ. Canine and feline cytology: A color atlas and interpretation guide. Saunders. $3^{\text {rd }}$ ed. 2015;544.

18. Rocha NS, Tremori TM, Carneiro JAM. Fine needle aspiration cytology in the diagnosis of canine cutaneus transmissible tumor - Case Report. Open Journal of Veterinary Medicine. 2014;4:204-209.

19. Dernell WS, Straw RC, Withrow SJ. Tumors of the skeletal system. In: Withrow, SJ, Macewen EG. Small animal clinical oncology. 3 ed. Philadelphia: W. B. Saunders. 2001;378-417.

20. Chun R, Lorimier LP. Update on the biology and management of canine osteosarcoma. In: Kitchell BE. The veterinary clinics of North America: Small animal practice. 1. Ed. Philadelphia: W.B. Saunders Company. 2003;492-516.

21. Straw RC. Tumors of the skeletal system. In: Withrow SJ, Macewen EG. Small animal clinical oncology. 2. Philadelphia: W.B. Saunders Company. 1996;378-417.

22. Daleck CR, Canola JC, Stefanes SA, et al. Retrospective study of primary osteosarcoma of bones in dogs for 14 mounths. Brazilian Journal of Veterinary
Research Animal Science. 2006;43:125131.

23. Liptak JM, Ehrhart N. Bone and joint tumors. In: Ettinger SJ, Feldman EC. Textbook of Veterinary Internal Medicine. 6. ed. Missouri: Elsevier Saunders. 2005;1: 761-773.

24. Spodnick GJ, et al. Prognosis for dogs with appendicular osteosarcoma treated by amputation alone: 162 cases (1978-1988). Journal of American Veterinarian Medical Association. 1992;200:995-999.

25. Ogilvie GK. Bone tumors. In: Rosenthal RC. Veterinary oncology secrets. 1 ed. Philadelphia: Hanley \& Belfus. 2001;139147.

26. Cooley DM, Waters DJ. Skeletal neoplasms of small dogs: A retrospective study and literature review. Journal of American Animal Hospital Association. 1997;33:11-23.

27. Terracini G, Glickman B. Host related risk factors for canine osteosarcoma. The Veterinary Journal. 1998;156:31-39.

28. Shapiro W, Fossum TW, Kitchell BE, Couto CG, Theilen GH. Use of cisplatin for treatment of appendicular osteosarcoma in dogs. Journal of the American Veterinary Medical Association. 1998;192:507-511.

29. Cavalcanti JN, Amstalden EMI, Guerra JL. Osteosarcoma in dogs: Clinicalmorphological study and prognostic correlation. Brazilian Journal of Veterinary Research Animal Science. 2004;41(5).

30. Silveira PR, Daleck CR, Eurides D, et al. Retrospective study of apendicular osteosarcoma in dogs. Ciência Animal Brasileira. 2008;9(2):487-495.

31. Heymann SJ, Diefenderfer DL, Goldschmidt MD, Newton CD. Canine axial skeletal osteosarcoma: A retrospective study of 116 cases (1986 to 1989). Veterinary Surgery. 1992;21:304-310.

32. Bersano PRO, Floresti GV, Figueiroa FC, Rocha NS. Osteossarcoma in na ireland setter: Case report. Veterinária e Zootecnia. 2008;15(3):72-74.

33. Moore AS. Osteosarcoma in dogs: Managing a destructive disorder. Veterinary Medicine. 2001;96(7):539-546,.

34. Mauldin GN, Matus RE, Withrow SJ, et al. Canine osteosarcoma: Treatment by amputation versus amputation and adjuvant chemotherapy using doxorubicin and cisplatin. Journal of Veterinary Internal Medicine. 1988;2(4):177-180. 
35. Patnaik AK. Canine extraskeletal osteosarcoma and chondrosarcomas: A clinicopathologic study of 14 cases. Veterinary Pathology. 1990;27(1):46-55.

36. Rodrigues BA, Faraco C, Oliveira R, et al. Pelvic osteosarcoma ressection in a bitch: Case report. Arq. Bras. Med.Vet. Zootec. 2009;61(1).

37. O'brien MG, Straw RC, Withhrow SJ, Powers BE, Jameson VJ, Lafferty M, Ogilvie GK, Larue SM. Resection of pulmonary metastases in canine osteosarcoma: 36 cases (1983-1992). Veterinary Surgery. 1993;22:105-109.

38. Teixeira LV, Martins DB, Fighera R, Lopes STA. Clinic study of canine osteosarcoma. Acta Scientiae Veterinarie. 2010;38:185190.

39. Lipitak JM, Dernell WS, Ehrhart NP, Withrow SJ. Canine appendicular osteossarcoma: Diagnosis and palliative treatment. Compedium of Continuing Education for the Practising Veterinarian. 2004;26:172-182.

(c) 2016 Wilmsen et al.; This is an Open Access article distributed under the terms of the Creative Commons Attribution License (http://creativecommons.org/licenses/by/4.0), which permits unrestricted use, distribution, and reproduction in any medium, provided the original work is properly cited.

Peer-review history:

The peer review history for this paper can be accessed here: http://sciencedomain.org/review-history/12591 